\title{
Current electromagnetic research in Denmark
}

\section{Christiansen, Peter Leth}

Published in:

Antennas and Propagation Society International Symposium

Publication date:

1973

Document Version

Publisher's PDF, also known as Version of record

Link back to DTU Orbit

Citation (APA):

Christiansen, P. L. (1973). Current electromagnetic research in Denmark. In Antennas and Propagation Society International Symposium (Vol. Volume 11, pp. 208-211). IEEE.

\section{General rights}

Copyright and moral rights for the publications made accessible in the public portal are retained by the authors and/or other copyright owners and it is a condition of accessing publications that users recognise and abide by the legal requirements associated with these rights.

- Users may download and print one copy of any publication from the public portal for the purpose of private study or research.

- You may not further distribute the material or use it for any profit-making activity or commercial gain

- You may freely distribute the URL identifying the publication in the public portal

If you believe that this document breaches copyright please contact us providing details, and we will remove access to the work immediately and investigate your claim. 


\author{
P.L. Christiansen \\ Laboratory of Applied Mathematical Physics \\ Technical University of Denmark \\ Lyngby, Denmark
}

Eight research projects have been selected to give an impression of current electromagnetic research in Denmark. This activity owes a great deal to the Laboratory of Electromagnetic Theory founded in 1954 by Professor Lottrup Knudsen at the Technical University of Denmark. Thus a majority of the following authors outside this place has earlier been affiliated with the laboratory.

studies in hereditary electromagnetism. P.W. Karlsson, Physics Laboratory II, Technical University of Denmark, Lyngby, Denmark.

The problem considered consists in establishing boundary conditions for the field vectors as well as conditions upon quantities appearing in the constitutive equations, such that the electromagnetic field (1) is uniquely determined, and (2) has a finite velocity of propagation. A theorem of this kind was proved by Rubinowicz in 1926 for constant material parameters. As a generalization, we have considered constitutive equations involving hereditary terms, i.e., integrals, with material-describing kernels, of independent field variables over the past at the position in question, or over the "past" hypercone in four-dimensional space-time; the materials may be non-linear, anisotropic, inhomogeneous and non-stationary. For this case, conditions implying (1) as well as (2) have been found.

Wave propagation in stratified, moving media. S. Berntsen and G. Johannsen, Electrical Department, Danish Engineering Academy, Aalborg, Denmark.

In recent years numerous authors have examined wave propagation in stratified media of different structure. Wong and cheng (1) thus calculated the scattered fields from a circular cylinder coated with an inhomogeneous plasma by means of a stratification technique using $4 \times 4$ transmission matrices in oroer to avoid large numbers of simultaneous equations. Kong (2) treated a plane n-layer structure, in which the layers are in relative motion, in a similar manner.

The present work is a general investigation of the $4 \times 4$ matrix method, which seems only applicable in rectanguzar and circular structures. If the layers are moving with different velocities no common rest frame obviously exists, but a Lorentz-invariant formulation can easily be obtained. A suitable choice of inertial frame for each layer turns out to facilitate the computation. The formalism will also be applied to wave guides.

1. W.C. Wong and D.K. Cheng (1968 Proc. IEE 115, p. 1446).

2. J.A. Kong (1971 Can. J. Phys. 49, p. 2785 ). 
Propagation in an evaporation duct. H. Bach, Laboratory of Electromagnetic Theory, Technical University of Denmark, Lyngby, Denmark.

The propagation in an atmospheric superrefractive layer above the sea is investigated. Here an evaporation duct, in which the refractive index first decreases with height and later increases again, is known to exist. A smooth profile is modelled by means of two parabolic segments and a semi-infinite line with a slope corresponding to standard atmospheric conditions.

The eigenvalues of the corresponding mathematical problem is determined by numerical means, and curves for attenuation factors and height-gain functions are computed. The results show good agreement with results obtained by means of the phase integral method.

The technique has been used in connection with propagation in an evaporation duct above a rough sea surface. It turns out that the attenuation due to leakage and due to scattering losses is of the same order of magnitude in practical cases.

Future work on bringing the computer programs into a form which is suitable for radar forecasting is planned.

A comparative study of diffraction processes in geometrical diffraction theory. P.I. Christiansen, Laboratory of Applied Mathematical Physics, Technical University of Denmark, Lyngby, Denmark.

The literature shows an increasing number of time-harmonic solutions to scattering problems concerning halfplanes and wedges with various boundary conditions at the bounding halfplanes. From the far field expansion of these solutions diffraction coefficients describing the diffraction process at the edge of the scatterer can be extracted and used in the geometrical diffraction theory.

In the present work the scalar diffraction process at a wedge with two different surface impedances is analysed. When the wedge reduces to a halfplane with the same surface impedance on both sides the description of the diffraction process can be generalized to the plasma case where two modes of propagation exist outside the halfplane. The diffraction coefficient then describes the process by which an incident ray produces a diffracted ray of the same mode as the incident ray. The diffraction process by which the mode is converted can also be handled by these considerations.

The possibility of a prediction of the (unknown) diffraction coefficients for a wedge in a plasma is aiscussed. 
Numerical determination of radiation patterns for wire antennas on conducting bodies. N.C. Albertsen, J.E. Hansen, and N.E. Jensen, Laboratory of Electromagnetic Theory, Technical University of Denmark, Lyngby, Denmark.

In contract with the European Space Research Organization, a theoretical formulation has been developed for the determination of radiation patterns of thin wire antennas on conducting bodies. Using this formulation a computer program has been constructed with the purpose of analysing the radiation from monopole antennas on a small scientific satellite body of cylindrical shape on which a number of straight, passive antennas may also be attached.

The method uses a combination of two integral equations for the unknown current distributions. An integral equation for the electric field is applied for the passive and driven wire antennas. For the satellite body itself, a magnetic field integral is used. This procedure exploits the individual properties of electric and magnetic field integral equations. The complete electromagnetic problem is in this way formulated in terms of simultaneous integral equations which are solved numerically by the method of moments.

A number of test runs for monopoles on cylinders has been made. The results agree well with radiation patterns obtained experimentally in the Anechoic Chamber at the Technical University.

Theoretical investigation of a double grid reflector antenna system for satellite communication*. J. Jacobsen and o. Sønder, Terma Elektronisk Industri A/S, Aarhus, Denmark.

A new type of reflector antenna with polarization cleaning properties has been investigated. This antenna is particularly intended for transmission of two signals with orthogonal polarizations within the same antenna beam (dual polarization mode transmission). For this application a high degree of polarization purity is required.

The double grid reflector consists of two orthogonal sets of thin, parallel metallic plates. The edges of the two sets of plates lie on two slightly displaced paraboloidal surfaces with parallel focal axes. Each surface is illuminated by a feed horn located at the focal point for the surface and linearly polarized parallel to the plates. Thus each horn is focused with respect to the corresponding grid surface but defocused with respect to the other, such that the unwanted cross-polarized field does not radiate in the direction of the focal axes of the system.

The analysis was carried out by means of a modified version of the physical optics method. This version uses the scattering matrix for an infinite plane model of the double grid structure.

The polarization cleaning effect has been computed. A reduction of the cross-polarized field from $-32 \mathrm{~dB}$ (solid reflector) to -53 $\mathrm{dB}$ (double grid reflector) below the maximum of the principal field was found. An experimental verification has been planned.

* This work was sponsored by ESTEC/Contract No. 1702/72AA. 
Riometer measurements in the polar region. P. Stauning, Ionosphere Laboratory, Danish Meteorological Institute, Iyngby, Denmark.

Since the International Geophysical Year (1957/58) the riometer (Relative Ionospheric Opacity-meter) measurements of cosmic noise absorption have been a valuable tool for investigations of geophysical disturbances causing absorption of HF-radio weves in the ionosphere.

Presently the Ionlab riometer project comprises a set-up of 14 riometers at various observetories in Greenland, at Faroe Islands and at Spitsbergen. The riometer net is primarily intended to provide data for studies of the relations of absorption events in the auroral and polar regions to the energetic particle radiation produced during solar flare events and during magnetospheric substorms. The data are also used for investigation of problems related to the HF-radio communication in Greenland.

In the time up to the International Year of Magnetospheric Studies (1975/76) the number of Ionlab riometer observatories will be further increased to enable a detailed analysis of the temporal and geographical development of polar absorption events. When combined with satellite particle data, such a riometer set-up may prove a unique tool for investigations of the complicated structure of the geomagnetic field extending from the polar cap into the outer magnetosphere and tail regions.

Radio echo sounding of polar ice*. P. Gudmandsen, Laboratory of Electromagnetic Theory, Technical University of Denmark, Lyngby, Denmark.

Radio echo sounding of the inland ice in Greenland is carried out. The program comprises development of suitable apparatus and measuring techniques as well as surveying the inland ice.

At present two pulse radars at $60 \mathrm{MHz}$ and $300 \mathrm{MHz}$ installed in a C-130 Hercules aircraft are used for the sounding. The echo records are continuous films of intensity modulated oscilloscopes.

For the interpretation of the records studies are made of the refractive properties of the layered medium of polar ice with density variations and surface ondulations. Also the total two-way absorption of the inland ice has been calculated based on a theoretical model of the temperature profile of the ice.

Extensive scattering of the radio waves occurs in some areas of Greenland for unknown reasons and makes the sounding very difficult. Remarkable stratifications are observed on the records for the greater part of Greenland. The origin of the layer echoes is still unknown but play an important role in glaciological studies of the flow of the ice.

The current development coneerns the introduction of new techniques to overcome propagation problems in Greenland and Antarctica.

* The work is supported by The Ministry for Greenland and the U.S. National Science Foundation. 